Running Head: Renewal of instrumental avoidance

\title{
Renewal of instrumental avoidance in humans
}

\author{
Gonzalo P. Urcelay ${ }^{1}$, Kadell Symmons ${ }^{1}$, \& Arthur Prével ${ }^{2}$
}

${ }^{1}$ Department of Neuroscience, Psychology \& Behaviour, University of Leicester, UK.

${ }^{2}$ Department of Experimental Psychology, Ghent University, Belgium.

Corr. author: Gonzalo P. Urcelay

Department of Neuroscience, Psychology and Behaviour.

University of Leicester

Lancaster Rd. Leicester, LE1 7HA, UK

TEL: $\quad$ +44 (0116) 229-7173

E-mail: gpu1@le.ac.uk 


\begin{abstract}
(max 200 words)
Avoidance behaviour is a hallmark of anxiety disorders and OCD, yet there is a pressing need to understand how extinction of avoidance responses proceeds and what variables if any determine recovery from extinction. In this study, we used a within-subjects design in which participants learned to avoid a loud noise signalled by two discrete visual stimuli (CSs+), by pressing the space bar in the computer keyboard. We trained each CS+ along with a CS- in a different context. During extinction, CSs+ and CSs- stimuli were presented in the alternative context from that of training , and participants were allowed to freely respond, but no loud noise was presented. Finally, all CSs were tested in both contexts, resulting in a within-subjects $A B A$ vs $A B B$ comparison. Participants increased avoidance responses over training, and decreased responding during extinction. During test, responding was significantly higher when CS+ stimuli were tested in the training vs the extinction context, thus showing renewal of instrumental avoidance in humans. Additional analyses revealed substantial individual differences in this task. This study shows renewal of instrumental avoidance in humans, and the design can shed light on ways of making extinction more durable.
\end{abstract}

Key Words: Instrumental avoidance; extinction; renewal; anxiety disorders 


\section{Renewal of instrumental avoidance in humans}

\section{Introduction}

Anxiety disorders and post-traumatic stress disorder (PTSD) are a group of disabling disorders, which result from individuals showing disproportional fear to objects or situations, and excessive active avoidance of potential threats. These symptoms are apparently irrational but lead to considerable distress and social isolation. Much like anxiety disorders and PTSD, obsessivecompulsive disorder (OCD) also shows excessive avoidance along with other symptoms such as checking (which itself can be characterized as avoidance). Across all these conditions, excessive avoidance behaviour is a hallmark of the behavioural manifestations, a diagnostic criterion, and sometimes a predictor of treatment (Aderka, McLean, Huppert, Davidson, \& Foa, 2013). In addition, recent dimensional attempts to overcome the categorical nature of DSM-V (American Psychiatric Association, 2013) have identified Research Domain Criteria (RDoC: Insel et al, 2010), and in this scheme avoidance is a behavioural element of aversively motivated behaviours. Despite the prevalence and clinical relevance of avoidance behaviour, it is only recently that interest in, and studies investigating avoidance have re-emerged (Cain, 2019; Dymond, 2019; Gillan, Urcelay \& Robbins, 2015; LeDoux et al., 2016; Pittig, Treanor, LeBeau, \& Craske, 2018; Urcelay \& Prével, 2019) after three decades with little research on this area. This may be due to a long-standing overemphasis on studying and treating fear itself instead of avoidance behaviour. Interest in avoidance behaviour however has resurged in the last decade, leading to numerous reviews on avoidance, and two specialized volumes (see Beckers \& Craske, 2017; Servatius, 2016 for introduction by editors). The resurged interest for avoidance behaviour may be due in part to the finding that avoidance behaviour itself can protect from fear extinction (Lovibond, Mitchell, Minard, Brady \& Menzies, 2009), which is central to exposure-based therapies, leading sometimes to extremely persistent fear and avoidance behaviours (Williams \& Levis, 1991).

Extinction learning has been proposed as a laboratory analogue of exposure-based therapies, in part because of the striking parallels between extinction learning and exposure based therapies. One of the cardinal features of extinction learning is that, rather than erasing the original memory, it 
results in new inhibitory learning, which is context dependent (Bouton, 1993; 2004). This is supported by behavioural evidence showing at least eight phenomena documenting recovery from extinction (Urcelay, 2012). Three of these phenomena, namely spontaneous recovery, reinstatement, and renewal, have been widely studied in humans and other animals (Bouton, 1993; 2004, Urcelay, 2012). Following fear conditioning and extinction, spontaneous recovery is the return of excitatory learning that is observed when a retention interval is interposed between extinction and testing. Reinstatement is a similar recovery that results from re-exposure to the aversive event. Finally, renewal is the recovery from extinction that is typically observed when participants are tested outside of the context in which extinction took place. These three phenomena have gained attention because they parallel return of fear following exposure based therapies, which happens with the passage of time (spontaneous recovery), upon re-exposure to feared stimuli and stress (reinstatement), and when patients leave the therapist's office (renewal). Whilst these three phenomena have been widely documented following extinction of fear conditioning, there is a dearth of studies investigating recovery from extinction of avoidance behaviour (Urcelay \& Prével, 2019).

In this study, we investigated renewal of instrumental avoidance in humans, and assess whether there are significant individual differences in avoidance learning, extinction and renewal. Because most often than not patients receive exposure therapy in a particular context or setting, renewal has proven a potent tool to investigate return of fear that occurs outside of the therapist's office. As mentioned, the renewal effect happens when, following extinction learning, participants are tested in a context different from that of extinction learning. Assuming that excitatory learning happens in context $A$, extinction can occur in the same $(A)$ or a different context $(B)$, and testing can occur in the same context as acquisition and extinction (AAA), in the context of extinction learning $(A B B)$, in the context of acquisition when extinction was conducted in a different context (ABA), or when test happens in a context different from that of acquisition and extinction ( $A A B$ or $A B C)$. All three conditions in which testing is conducted outside of the context of extinction (ABA, $A B C, A A B)$ result in recovery from extinction (Bouton, 2004; Urcelay, 2012). Although renewal of avoidance has been documented in rodents (Nakajima, 2014), it is surprising that there are no reports documenting 
renewal of avoidance behaviour in humans. Given that avoidance behaviour is a hallmark of anxiety disorders, we sought to document this phenomenon in humans using an aversively motivated task. We adapted the protocol pioneered by Flores and her colleagues (Flores, López, Vervliet, \& Cobos, 2018) and used a within-subjects design (Rescorla, 2008) to investigate renewal of instrumental avoidance in healthy human participants. The unique advantage of this design is that it matches the two contexts for their overall history of reinforcement during acquisition and non-reinforcement during extinction, and the conditioned stimuli (CSs) in terms of histories of reinforcement and nonreinforcement. In addition to reducing the number of participants needed, this design renders any differences observed at test attributable to modulatory effects of the context, which is consistent with the best-developed explanation for the context-dependence of extinction (Bouton, 1993).

\section{Method}

\section{Participants}

The participants were 30 undergraduate students from the University of Leicester that completed the study in exchange for course credit. Twenty-five identified themselves as female and 5 as males, their ages ranged from 18 to 25 years $(M=20.43, S D=1.41)$. Participants were recruited via an online system where they signed up in return for course credits. The University of Leicester Ethics Review committee approved the study, in accordance with the Code of Ethics of the World Medical Association.

\section{Apparatus and Materials}

The experiment was run in three separate rooms, each containing a chair and desk with a computer. Three Helwet-Packard PCs with Windows operating system were used to run the task, which was programmed in Matlab using the Psychtoolbox interface. The stimuli were presented using 19.0" Neovo F-419 monitors (SXGA 1280 x 1024 resolution), placed roughly $60 \mathrm{~cm}$ in front of the participants. Avoidance responses were made through a keyboard by pressing the spacebar. Four fractals $(10 \times 8.5 \mathrm{~cm})$ were used as stimuli $(\mathrm{CS} 1, \mathrm{CS} 2, \mathrm{CS} 3, \mathrm{CS} 4)$ and these were randomized across participants by the program. A 3-second tone of $1100 \mathrm{~Hz}(95 \pm 4 \mathrm{~dB})$ was presented bilaterally through dynamic stereo headphones and served as the aversive outcome. A few participants mentioned that 
the noise was too loud, and for these the loud noise was reduced to $90 \mathrm{~dB}$. Before starting the experiment, participants completed Spielberger's State-Trait Anxiety Inventory for adults (Spielberger, Gorsuch, Lushene, Vagg, Jacobs, 1983), which consists of 40 items, 20 of these assessing State Anxiety and the remaining 20 assessing Trait Anxiety. Items are rated on a Lickert scale ranging from 0 to 3.

Design

This study was run using a within-subjects design (see Table 1), adapted from the design used by Rescorla (2008). Two contexts were created by changing the colour of the background (green or pink) of the screen where the stimuli were presented. In Context A, CS1 was always (i.e., continuous reinforcement) paired with the loud tone, whereas CS2 was never paired with the loud tone. In Context B, CS3 was similarly paired with the tone whereas CS4 was not. Following Pavlovian conditioning and Instrumental Acquisition phases, CS1 and CS3 were presented in the alternative context (CS1 was presented in Context B, and CS3 in Context A), and participants were allowed to press the spacebar but the loud tone was never presented (extinction). During this phase, CS2 and CS4 were also presented in the alternative context, in the absence of the loud tone. All stimuli were tested in the Acquisition and Extinction contexts, with the order counterbalanced between participants. Thus, all stimuli were tested (Test phase) in the same context in which extinction took place, or in the context where acquisition took place, resulting in a within-subjects $A B B$ vs $A B A$ comparison (where $A$ is the context of acquisition and B the context of extinction).

\section{Procedure}

Upon arriving in the laboratory, participants signed a consent form informing them that there will be images that may be paired with a loud noise as part of the experiment, and they would eventually have the opportunity to avoid the loud noise by using the keyboard. After giving informed consent, participants completed the STAI questionnaires, and then started the experiment. The experiment itself was divided into 4 phases: a Pavlovian learning phase, an instrumental learning phase, an extinction phase, and a test phase. Participants began by wearing the headphones given, and reading the instructions pertaining to the first phase. The instructions read: "In this experiment, 
you will see different fractal images on the screen. Some of these will be followed by an aversive sound (that will be played through the headphones), but some will not. At this stage, your task is to determine which images are followed by the annoying sound, and which ones are not. Note that there will also be changes in the background colour of the screen. In addition, you should try to determine when the sound is to appear. Press the SPACE bar to continue”. During each trial, the background was the first thing presented for 3 seconds. Following this, one of the four images (CS1, CS2, CS3, and CS4) was displayed in the centre of the screen for 20 seconds. In this and all other phases, the CSs were always presented for 20 seconds, regardless of whether participants avoided the loud noise or not. The onset of the noise was programmed according to a variable time schedule with a mean of 9 seconds (from the onset of the CSs+), which followed a rectangle distribution with range of 15 seconds. This way, the aversive sound could appear randomly at any second between 2 and 16 seconds from the onset of the CSs+. The Pavlovian learning phase consisted of 4 trial blocks each including 2 presentations of each CS, the order in which each CS was presented was randomised (as was the case throughout) as well as the specific image that triggered the aversive sound also being randomised. Each CS was presented 8 times during this phase.

After the Pavlovian phase, participants read the instructions for the instrumental phase. "This phase is identical to the previous phase, except you can now avoid the sound by pressing the space bar. Critically, for a press to be successful, it has to be emitted within one second before the sound is presented. You can press the space bar as many times as you wish nevertheless, but only those presses within one second of the appearance of the noise will prevent the noise from happening. Your task it to try to avoid as many presentations of the noise as possible. Press the SPACE bar to continue". The instrumental phase also consisted of 4 trial blocks each including 2 presentations of each CS that was randomised, therefore having 8 presentations for each CS during this phase. After the instrumental phase, participants began the extinction phase which did not have any instructions beforehand, so the transition from the instrumental to the extinction phase was seamless. During this phase however, the $2 \mathrm{CSs}+$ were presented against the opposite background as was the case with the 2 CS- (see Table 1). During this and the Test phases, the aversive sound was never presented, 
but spacebar responses were still permitted. The extinction phase consisted of 8 blocks of randomised CS presentations, therefore each CS was presented 16 times during this phase. Lastly, all stimuli were tested in both contexts, with the order of context counterbalanced across participants. This phase consisted of blocks in which there were 2 presentations of each CS. Data Analysis

The main dependent measure in this study was the number of presses per stimulus in each block (each block containing 2 stimuli presentation) across both CS+ and both CS-. The reasoning for collapsing across CSs is that these always received the same training across all phases. Thus, during acquisition we summed the avoidance responses across the 2 presentations of each CS, and averaged the two CSs+ and the two CSs- in each block (4 blocks). The same was done for the 8 extinction blocks, and each test block. Space bar presses were analysed with within-subjects ANOVAS with stimulus identity (CSs+ vs CSs-) and blocks (1-4 during training, and 1-8 during extinction) as within-subjects variables. During test, we used within subjects ANOVAS and compared stimuli (CSs+ vs CSs-) and context of Test (Extinction vs Acquisition). Visual inspection of avoidance responses during extinction revealed that some participants ceased responding early on, whist other participants never ceased responding. Therefore, we divided the sample on the basis of when participants ceased responding (Extinction: complete cessation during the first 4 blocks of extinction; NoExtinction: during the last 4 blocks of extinction). The results were re-analysed with this factor as a between-subjects variable. Omnibus ANOVAS were followed with analyses for CS type across blocks

during Acquisition and Extinction, and Context during Test. When sphericity was violated, we used the Huynh-Feldt adjustment. In all cases we report partial eta squared as a measure of the unbiased, effect size (Cohen, 1992).

\section{Results}

\section{Acquisition}

Figure $1 \mathrm{~A}$ depicts the acquisition of instrumental avoidance for both CSs+ (CS1 and CS3) and both CSs- (CS2 and CS4) across 4 blocks of training. All participants learned to avoid during CSs+ presentations. Avoidance responses increased across blocks for CSs+, but not for CSs-. These 
impressions were supported by a 2 (Stimulus: CSs+ vs CSs-) x 4 (Block: 1-4) within-subjects ANOVA, that revealed a main effect of Stimulus, $F(1,29)=42.81, p<.001, \eta p^{2}=0.596$, an effect of Block, $F$ $(1.47,42.85)=10.69, p<.01, \eta p^{2}=0.26$, and a Stimulus $x$ Block interaction, $F(1.44,41.85)=8.89, p$ $<.01, \eta p^{2}=0.23$. Analyses of simple effects revealed a large effect of block for CSs,$+ F(1.44,41.95)$ $=9.97, p<.01, \eta p^{2}=0.25$, but only a marginal effect for CSs- $F(1.36,39.59)=3.45, p=.058, \eta p^{2}=$ 0.10. Thus, the interaction suggests that acquisition was observed for CSs+, but not for CSs-.

\section{Extinction}

Figure 1B shows the spacebar presses during 8 blocks of extinction for CSs+ and CSs-. As it can be appreciated in the figure, extinction was observed for CSs+, whilst CSs- only showed a small change early during the extinction session, perhaps reflecting the uncertainty produced by the extinction contingency and the changes in context. These impressions were supported by the following statistical analyses. A 2 (Stimulus: CS+ vs CSs) x 8 (Block: 1-8) within-subjects ANOVA revealed a main effect of Stimulus, $F(1,29)=21.81, p<.001, \eta p^{2}=0.42$, a main effect of Block, $F$ $(1.49,43.24)=10.56, p<.01, \eta p^{2}=0.26,95 \%$, and a Stimulus $x$ Block interaction, $F(1.75,50.81)=$ 8.52, $p<.01, \eta p^{2}=0.22$. To follow up the Stimulus $\times$ Block interaction, we tested if there was a change across blocks for each stimuli separately. These analyses revealed a clear effect of Block for CSs $+, F(1.65,47.96)=11.53, p<.001, \eta p^{2}=0.28$, but only a marginal change for CSs-, $F(1.12$, 32.58) $=3.07, p=.085, \eta p^{2}=0.09$.

Test

Figure $1 \mathrm{C}$ shows the results during the test sessions. As it is clear from the figure, participants responded more to the CSs+ when these were tested in the Acquisition context relative to the Extinction context. On the contrary, no effect of context change was observed for CSs-. The test data were analysed with a 2 (Stimulus: CS+ vs CS-) x 2 (Context: Acquisition vs Extinction) within-subjects ANOVA, which revealed an effect of Stimulus, $F(1,29)=21.36, p<.001, \eta p^{2}=0.42$, and effect of Context, $F(1,29)=9.71, p<.01, \eta p^{2}=0.25$, and a Stimulus by Context interaction, $F(1,29)=9.15$, $p<.01, \eta p^{2}=0.24$. A comparison of avoidance responses during CSs+ in both contexts revealed more responding in the Acquisition context, $F(1,29)=9.44, p<.01, \eta p^{2}=0.24$, but no differences 
were observed for CSs-, $F(1,29)=.96, p=.33, \eta p^{2}=0.03$. Thus, consistent with the expectations, we observed a significant renewal effect when testing was conducted in the acquisition context relative to the extinction context. In addition, because this within-subjects design equates the associative strength of both contexts, we did not observe any differences in responding to the CSsbased on test context.

\section{Individual differences}

Correlational analyses did not reveal any meaningful results, perhaps due to the low and narrow range of scores in the sub-questionnaires, STAI-S $(M=35.43, S D=7.51)$ or STAI-T $(M=$ 43.93, $S D=9.46)$. However, visual inspection of responding during extinction revealed that some participants extinguished (i.e., ceased responding upon presentation of the CSs+) early during extinction, whilst some participants continued responding during extinction sessions, even during block 8 of extinction. In order to capture these differences between participants in terms of extinction, we divided our sample into two subgroups. Group Extinction $(n=18)$ contains participants that stopped responding within the first 4 blocks of extinction, and Group NoExtinction $(n=12)$ contains participants that continued responding through Blocks 5-8. We analysed the training data to see if participants in Group Extinction differed from those in Group NoExtinction, with a 2 (Extinction Group:

Extinction vs NoExtinction) $\times 2$ (Stimulus: CSs+ vs CSs-) $\times 4$ (Block: 1-4) mixed ANOVA, that revealed (in addition of what is reported above) a main effect of Extinction Group, $F(1,28)=4.48, p<.05, \eta p^{2}$ $=0.13$, and a marginally significant Extinction Group $x$ Stimulus interaction, $F(1,28)=3.91, p=.058$, $\eta p^{2}=0.12$. Simple comparisons between Extinction Groups in terms of responding during acquisition revealed a difference to the CSs+, $F(1,28)=4.26, p<.05, \eta p^{2}=0.13$, but not to the CSs-, $F(1,28)=$ $.008, p=.931, \eta p^{2}=0.00$. This suggests that participants that showed extinction responded much more to the CSs+ during acquisition than those that did not show extinction (Fig 2A). We discuss this in the General Discussion.

Analysis of responding during extinction revealed, as expected because we used extinction performance as a criterion, differences between the groups in the rate of extinction (Fig 2B). A 2 (Extinction Group: Extinction vs NoExtinction) x 2 (Stimulus: CS+ vs CS-) x 8 (Blocks: 1-8) mixed 
ANOVA revealed (in addition of what is reported above) a Extinction Group x Stimulus interaction, $F$ $(1,28)=4.30, p<.05, \eta p^{2}=0.13$, a Extinction Group x Block interaction, $F(1.55,43.65)=5.78, p<$ $.05, \eta p^{2}=0.17$, and a triple Extinction Group $x$ Stimulus $x$ Block interaction, $F(1.93,54.22)=5.97, p<$ $.01, \eta p^{2}=0.17$. Analyses of avoidance responses to the CSs+ during extinction for each sub-group separately revealed a large effect of Blocks for Group Extinction, $F(1.76,29.97)=15.03, p<.001$, $\eta p^{2}=0.46$, but no change in responding during blocks of extinction in Group NoExtinction, $F(1.59$, $17.54)=0.43, p=.60, \eta p^{2}=0.03$. Finally, analysis of avoidance responses during the test session (Fig 2C) for these two sub-groups was conducted with a 2 (Extinction Group: Extinction vs NoExtinction) x 2 (Stimulus: CS+ vs CS-) x 2 (Context: Acquisition vs Extinction) mixed ANOVA, which in addition to the above analysis revealed a Extinction Group $x$ Context interaction, $F(1,28)=$ 6.75, $p<.05, \eta p^{2}=0.19$, and a triple Extinction Group $\times$ Stimulus $\times$ Context interaction, $F(1,28)=$ $7.30, p<.05, \eta p^{2}=0.20$. The triple interaction was followed up with separate analysis comparing responding to the CSs+ in the Acquisition and Extinction contexts (i.e., renewal) for each sub-group. This comparison suggested a large renewal effect in Group Extinction, $F(1,17)=14.64, p<.01, \eta p^{2}$ $=0.46$, but no renewal in Group NoExtinction, $F(1,11)=0.01, p=.91, \eta p^{2}=0.001$.

Overall, these analyses suggest that this avoidance paradigm implemented as a withinsubjects design yields a large within-subjects renewal effect, and that different participants adopted different strategies. This resulted in a group (Extinction) that was sensitive to the change in contingency imposed by extinction, and then showed a large renewal effect, whilst a second Group NoExtinction that, despite a lower rate of responding during acquisition, did not show any extinction, nor a renewal effect. We will further discuss these results in the General Discussion.

\section{General Discussion}

The purpose of this study was to develop a within-subjects experimental paradigm to study renewal of instrumental avoidance in humans. An additional objective was to ascertain if this paradigm is sensitive to individual differences in the way that participants respond during the task, and hence whether they show extinction and renewal or not. We adopted a within-subjects design proposed by Rescorla (2008) and used a task based on that developed by Flores and colleagues 
(Flores, López, Vervliet \& Cobos, 2018) that introduces uncertainty concerning when the aversive outcome is to occur, which results in high levels of avoidance behaviour. During instrumental training, we observed good discrimination between CSs+ and CSs-, and an increase in responding across blocks of training that was selective to the CSs+, as suggested by the interaction between stimuli and block during training. During extinction, we saw a selective decline in responding to the CSs+ without large changes in responding to the CSs-. There was a small increase in responding to the CSs- that occurred during early blocks of extinction, perhaps because participants that noticed the change in contingency began responding to the previously non-reinforced CSs-, a finding that is also observed in fear extinction experiments (e.g., Haesen \& Vervliet, 2015). During test, we observed higher levels of avoidance responding when CSs+ were tested in the Acquisition context relative to testing in the Extinction context, whilst no differences were observed in responding to the CSs-. Whilst renewal from extinction in humans has been documented numerous times (see Nelson, SanJuan, VadilloRuiz, \& Leon, 2011 for a clear demonstration in humans, and Vervliet, Baeyens, Van den Bergh, \& Herman, 2013 for a review in fear studies), our study represents a first demonstration of ABA renewal in human instrumental avoidance. Because the current design equates the associative history of contexts and CSs, the current results are best explained by Bouton's model that assumes that extinction is context-dependent new learning (Bouton, 1993).

Analysis of individual differences based on the behaviour during extinction (groups Extinction and NoExtinction) revealed a surprising pattern that we did not anticipate. It is widely assumed that exaggerated (or maladaptive) avoidance as seen in anxiety disorders and OCD prevents participants from noticing changes in contingencies as those resulting from extinction, because participants avoiding at high rates continuously postpone contact with the aversive outcome, and therefore never realize that they are on extinction (Dymond, 2019; Lovibond, 2006; Seligman \& Johnston, 1973). Based on this view, we anticipated that the group that did not show extinction (NoExtinction) would display high avoidance levels during acquisition, which is the opposite of what we observed. These findings may be explained by assuming that, following the instructions informing participants that they had to press within a second of the aversive outcome for successful avoidance, participants in the 
Avoidance renewal 13

NoExtinction group adopted a strategy by which they pressed steadily through the presentation of the CSs+, and continued through extinction and test sessions with this strategy of continuous, steady spacebar pressing. This would also explain the lack of a renewal effect in this subset of participants. In addition, it is possible that responding at high rates is paralleled with high variability in responding, and with high variability the participants are more likely to experience the correlation between response and outcome (or its absence) and hence notice when extinction has started (Dickinson, 1985). Unfortunately, we did not record the distribution of avoidance responses within CS presentations, so future experiments will need to investigate this. In addition, the pattern of avoidance responses during test in sub-group Extinction showed strong adherence to changes in context, suggesting that these participants have adopted a rule strategy such as: the loud noise is expected during CS1 in context A but not in context $B$, and the loud noise is expected during CS3 in context $B$ but not in context $A$. Thus, the results of this sub-group seem consistent with an expectancy account of avoidance (Lovibond, 2006). Unfortunately, we did not record any self-report measures, further experiments assessing participant's judgements in addition to instrumental responding may provide additional evidence to better understand the pattern of results observed in these sub-groups.

As we mentioned in the introduction, research on extinction of instrumental avoidance has been growing steadily in the last decade (see Dymond, 2019; Urcelay \& Prével, 2019 for recent reviews), however the scarce literature of recovery from extinction in human avoidance behaviour has been contradictory. In rodents, Nakajima (2014) conducted a thorough set of experiments investigating different forms of renewal following extinction, and Tapias-Espinosa and colleagues (Tapias-Espinosa, Kadar, \& Segura-Torres (2018) investigated spontaneous recovery following extinction, both using of 2-way suttle box avoidance. In humans, most studies have observed recovery from extinction assessed by expectancy ratings and skin conductance responses, but only a few reports have observed recovery from extinction as measured by avoidance responses. For example, following extinction of targets (CS+ and CS-) and generalized stimuli, Cameron Schlund and Dymond (2015) presented 3 shocks and observed a moderate reinstatement of avoidance to a CS-. Similarly, Krypotos and Engelhard (2018) conducted fear extinction following instrumental avoidance 
and afterwards they administered 3 shocks to the participants. This resulted in reinstatement of shock expectation but because they did not observe avoidance responses during extinction, they could not measure the extent to which this manipulation resulted in reinstatement of avoidance behaviour. Krypotos and colleagues (Krypotos, Effting, Arnaudova, Kindt \& Beckers, 2014) investigated the effect of fear extinction on avoidance tendencies (as distinct from instrumental avoidance responses, avoidance tendencies rely on automatic tendencies acquired through Pavlovian conditioning). Using an $A B A$ design, they observed a trend towards more avoidance tendencies in the training context $(A)$ but the specific comparison with avoidance tendencies in the extinction context (B) did not achieve statistical significance. Vervliet and Indekeu (2015) tested extinction of instrumental avoidance without the possibility of responding (as an attempt to model exposure with response prevention; ERP), and observed that extinction with response prevention resulted in recovery at test when the response was again available, regardless of whether extinction was experienced or informed. This finding, which in itself is problematic for ERP and expectancy theory, can be interpreted as renewal following the logic that avoidance acquisition occurs on a context $(A)$, removing the response during extinction creates a distinct context during extinction (B), which leads to recovery when participants have again the opportunity to avoid during test (A). This finding replicated a study using a platform-avoidance task in rats (Bravo-Rivera, Roman-Ruiz, Montesinos-Cartagena, \& Quirk, 2015). Overall, despite the recent interest in the extinction of avoidance, recovery from extinction achieved by context manipulations has not been clearly documented in human instrumental avoidance.

Given that avoidance is a hallmark of anxiety, PTSD and OCD, and renewal models return of fear (or relapse) that occurs when patients leave the therapist office, the current findings have a number of implications. First, a clear demonstration of renewal in human instrumental avoidance suggests that the principles governing extinction of human instrumental avoidance obey similar principles as those of human fear extinction, and of course extinction (Pavlovian and instrumental) in other animals (Todd, Vurbic \& Bouton, 2014). This means that much of what we know about extinction of fear can also be applied to avoidance behaviour, and this is relevant given recent suggestions that considering avoidance as part of the treatment (or as an adjunct to exposure therapy) can be 
Avoidance renewal 15

beneficial (Hofmann \& Hay, 2018; Treanor \& Barry, 2017). Second, a design that provides a clear demonstration of renewal in human instrumental avoidance will enable studies investigating the effectiveness of ERP upon changes in contextual background. Given that availability or not of the response can create different contexts, changes in physical background can help to determine whether these effects are additive or not, hence illuminating the interactions between these different factors. Third, safety signals and safety behaviours provide relief, and safety signals reinforce avoidance behaviour (Fernando, Urcelay, Mar, Dickinson \& Robbins, 2014; Vervliet, Lange \& Milad, 2017), but these also prevent extinction of fear (Lovibond, Mitchell, Minard, Brady \& Menzies, 2009; Volders, Meulders, De Peuter, Vervliet \& Vlaeyen, 2012), and hence their use in therapeutic settings is poorly understood. Assessing their role using a powerful renewal design will enhance our understanding of these interactions on a design that better models return of fear (i.e., relapse) outside of the extinction context. Finally, a clear renewal design allows to investigate ways of conducting extinction to attenuate recovery from extinction of instrumental avoidance, as it has been done in Pavlovian extinction paradigms (Urcelay, 2012). For example, studies in rodents investigating extinction of fear (Urcelay, Wheeler, \& Miller, 2009) and avoidance (Tapias-Espinosa, Kadar, \& Segura-Torres, 2018) have found that spacing extinction trials (or sessions) attenuates recovery from extinction, but little is known about this factor in the extinction of human instrumental avoidance.

In summary, we have provided what to the best of our knowledge is the first demonstration of renewal in human instrumental avoidance. We also observed some clear individual differences that deserve further investigation. That is, it is unclear now whether the distinction between Extinction and NoExtinction sub-groups is of clinical relevance, or if it is the result of task demands inherent in this laboratory preparation. Overall, we believe that this task and design have potential to develop basic research on extinction of human avoidance, with an emphasis of translating basic findings to clinical practice. Whilst there is more research needed in these areas, we believe that this is a first and important step towards the development of such basic knowledge. 


\section{References}

Aderka, I. M., McLean, C. P., Huppert, J. D., Davidson, J. R. T., \& Foa, E. B. (2013). Fear, avoidance and physiological symptoms during cognitive-behavioral therapy for social anxiety disorder. Behaviour Research and Therapy, 51, 352-358. https://doi.org/10.1016/i.brat.2013.03.007 American Psychiatric Association. (2013). Diagnostic and Statistical Manual of Mental Disorders: $D S M-V$. Washington, DC: American Psychiatric Association.

Beckers, T., \& Craske, M. G. (2017). Avoidance and decision making in anxiety: An introduction to the special issue. Behaviour Research and Therapy, 96, 1-2.

https://doi.org/10.1016/i.brat.2017.05.009

Bouton, M. E. (1993). Context, time, and memory retrieval in the interference paradigms of Pavlovian learning. Psychological Bulletin, 114, 80-99. https://doi.org/10.1037/0033-2909.114.1.80

Bouton, M. E. (2004). Context and behavioral processes in extinction. Learning \& Memory, 11, 485494. https://doi.org/10.1101//m.78804

Bravo-Rivera, C., Roman-Ortiz, C., Montesinos-Cartagena, M., \& Quirk, G. J. (2015). Persistent active avoidance correlates with activity in prelimbic cortex and ventral striatum. Frontiers in Behavioral Neuroscience, 9. https://doi.org/10.3389/fnbeh.2015.00184

Cain, C. K. (2019). Avoidance problems reconsidered. Current Opinion in Behavioral Sciences, 26, 917. https://doi.org/10.1016/j.cobeha.2018.09.002

Cameron, G., Schlund, M. W., \& Dymond, S. (2015). Generalization of socially transmitted and instructed avoidance. Frontiers in Behavioral Neuroscience, 9. https://doi.org/10.3389/fnbeh.2015.00159

Cohen, J. (1992). A power primer. Psychological Bulletin, 112, 155-159. https://doi.org/10.1037/0033$\underline{2909.112 .1 .155}$

Dickinson, A. (1985). Actions and habits: the development of behavioural autonomy. Philosophical Transactions of the Royal Society B, 308, 67-78. https://doi.org/10.1098/rstb.1985.0010 
Dymond, S. (2019). Overcoming avoidance in anxiety disorders: The contributions of Pavlovian and operant avoidance extinction methods. Neuroscience and Biobehavioral Reviews, 98, 61-70. https://doi.org/10.1016/i.neubiorev.2019.01.007

Fernando, A. B. P., Urcelay, G. P., Mar, A. C., Dickinson, A., \& Robbins, T. W. (2014). Safety signals as instrumental reinforcers during free-operant avoidance. Learning \& Memory, 21, 488-497. https://doi.org/10.1101//m.034603.114

Flores, A., López, F. J., Vervliet, B., \& Cobos, P. L. (2018). Intolerance of uncertainty as a vulnerability factor for excessive and inflexible avoidance behavior. Behaviour Research and Therapy, 104, 34-43. https://doi.org/10.1016/j.brat.2018.02.008

Gillan, C. M., Urcelay, G. P., \& Robbins, T. W. (2016). An associative account of avoidance. In R. A. Murphy \& R. C. Honey (Eds.), The Wiley handbook on the cognitive neuroscience of learning. (pp. 442-467). Wiley-Blackwell. https://doi.org/10.1002/9781118650813.ch17

Haesen, K., \& Vervliet, B. (2015). Beyond extinction: Habituation eliminates conditioned skin conductance across contexts. International Journal of Psychophysiology, 98, 529-534. https://doi.org/10.1016/i.ijpsycho.2014.11.010

Hofmann, S. G., \& Hay, A. C. (2018). Rethinking avoidance: Toward a balanced approach to avoidance in treating anxiety disorders. Journal of Anxiety Disorders, 55, 14-21. https://doi.org/10.1016/j.janxdis.2018.03.004

Insel, T., Cuthbert, B., Garvey, M., Heinssen, R., Pine, D. S., Quinn, K., ... Wang, P. (2010). Research domain criteria (RDoC): Toward a new classification framework for research on mental disorders. The American Journal of Psychiatry, 167, 748-751. https://doi.org/10.1176/appi.ajp.2010.09091379

Krypotos, A.-M., Effting, M., Arnaudova, I., Kindt, M., \& Beckers, T. (2014). Avoided by association: Acquisition, extinction, and renewal of avoidance tendencies toward conditioned fear stimuli. Clinical Psychological Science, 2, 336-343. https://doi.org/10.1177/2167702613503139 
Krypotos, A.-M., \& Engelhard, I. M. (2018). Testing a novelty-based extinction procedure for the reduction of conditioned avoidance. Journal of Behavior Therapy and Experimental Psychiatry, 60, 22-28. https://doi.org/10.1016/i.jbtep.2018.02.006

LeDoux, J. E., Moscarello, J., Sears, R., \& Campese, V. (2017). The birth, death and resurrection of avoidance: A reconceptualization of a troubled paradigm. Molecular Psychiatry, 22, 24-36. https://doi.org/10.1038/mp.2016.166

Lovibond, P. (2006). Fear and Avoidance: An Integrated Expectancy Model. In M. G. Craske, D. Hermans, \& D. Vansteenwegen (Eds.), Fear and learning: From basic processes to clinical implications. (pp. 117-132). Washington, DC: American Psychological Association. https://doi.org/10.1037/11474-006

Lovibond, P. F., Mitchell, C. J., Minard, E., Brady, A., \& Menzies, R. G. (2009). Safety behaviours preserve threat beliefs: Protection from extinction of human fear conditioning by an avoidance response. Behaviour Research and Therapy, 47, 716-720. https://doi.org/10.1016/i.brat.2009.04.013

Nakajima, S. (2014). Renewal of signaled shuttle box avoidance in rats. Learning and Motivation, 46, 27-43. https://doi.org/10.1016/i.Imot.2013.12.002

Nelson, J. B., Sanjuan, M. del C., Vadillo-Ruiz, S., Pérez, J., \& León, S. P. (2011). Experimental renewal in human participants. Journal of Experimental Psychology: Animal Behavior Processes, 37, 58-70. https://doi.org/10.1037/a0020519

Pittig, A., Treanor, M., LeBeau, R. T., \& Craske, M. G. (2018). The role of associative fear and avoidance learning in anxiety disorders: Gaps and directions for future research. Neuroscience and Biobehavioral Reviews, 88, 117-140. https://doi.org/10.1016//.neubiorev.2018.03.015

Rescorla, R. A. (2008). Within-subject renewal in sign tracking. The Quarterly Journal of Experimental Psychology, 61, 1793-1802. https://doi.org/10.1080/17470210701790099

Seligman, M. E., \& Johnston, J. C. (1973). A cognitive theory of avoidance learning. In: Contemporary approaches to conditioning and learning. Oxford: V. H. Winston \& Sons. 
Servatius, R. J. (2016). Editorial: Avoidance: From basic science to psychopathology. Frontiers in Behavioral Neuroscience, 10. https://doi.org/10.3389/fnbeh.2016.00015

Spielberger, C. D., Gorsuch, R. L., Lushene, R., Vagg, P. R., \& Jacobs, G. A. (1983). Manual for the State-Trait Anxiety Inventory. Palo Alto, CA: Consulting Psychologists Press.

Tapias-Espinosa, C., Kádár, E., \& Segura-Torres, P. (2018). Spaced sessions of avoidance extinction reduce spontaneous recovery and promote infralimbic cortex activation. Behavioural Brain Research, 336, 59-66. https://doi.org/10.1016/i.bbr.2017.08.025

Todd, T. P., Vurbic, D., \& Bouton, M. E. (2014). Behavioral and neurobiological mechanisms of extinction in Pavlovian and instrumental learning. Neurobiology of Learning and Memory, 108, 52-64. https://doi.org/10.1016/i.nlm.2013.08.012

Treanor, M., \& Barry, T. J. (2017). Treatment of avoidance behavior as an adjunct to exposure therapy: Insights from modern learning theory. Behaviour Research and Therapy, 96, 30-36. https://doi.org/10.1016/j.brat.2017.04.009

Urcelay, G. P. (2012). Exposure techniques: The role of extinction learning. In P. Neudeck \& H.-U. Wittchen (Eds.), Exposure therapy: Rethinking the model — refining the method. (pp. 35-63). New York, NY: Springer Science + Business Media. https://doi.org/10.1007/978-1-4614-3342$\underline{24}$

Urcelay, G. P., \& Prével, A. (2019). Extinction of instrumental avoidance. Current Opinion in Behavioral Sciences, 26, 165-171. https://doi.org/10.1016/j.cobeha.2019.01.018

Urcelay, G. P., Wheeler, D. S., \& Miller, R. R. (2009). Spacing extinction trials alleviates renewal and spontaneous recovery. Learning \& Behavior, 37, 60-73. https://doi.org/10.3758/LB.37.1.60

Vervliet, B., Baeyens, F., Van den Bergh, O., \& Hermans, D. (2013). Extinction, generalization, and return of fear: A critical review of renewal research in humans. Biological Psychology, 92, 5158. https://doi.org/10.1016/..biopsycho.2012.01.006

Vervliet, B., \& Indekeu, E. (2015). Low-cost avoidance behaviors are resistant to fear extinction in humans. Frontiers in Behavioral Neuroscience, 9. https://doi.org/10.3389/fnbeh.2015.00351 
Vervliet, B., Lange, I., \& Milad, M. R. (2017). Temporal dynamics of relief in avoidance conditioning and fear extinction: Experimental validation and clinical relevance. Behaviour Research and Therapy, 96, 66-78. https://doi.org/10.1016/..brat.2017.04.011

Volders, S., Meulders, A., De Peuter, S., Vervliet, B., \& Vlaeyen, J. W. S. (2012). Safety behavior can hamper the extinction of fear of movement-related pain: An experimental investigation in healthy participants. Behaviour Research and Therapy, 50, 735-746.

https://doi.org/10.1016/i.brat.2012.06.004

Williams, R. W., \& Levis, D. J. (1991). A demonstration of persistent human avoidance in extinction. Bulletin of the Psychonomic Society, 29, 125-127. https://doi.org/10.3758/BF03335212 


\section{Author Notes}

This research was supported by the Economic and Social Research Council (ES/R011494/1) awarded to Gonzalo Urcelay. The study was submitted by KS in partial fulfilment for the requirements of an undergraduate dissertation at the University of Leicester. The authors wish to thank Dr Alice Welham, Dr José Alcalá, and Dr Peter Lovibond for helpful comments on a previous version of this paper, and Richard Kirkden for technical assistance. These findings were presented by Urcelay, Symmons and Prével at the International Meeting of the SEPC held in Malaga (September, 2019). 
Table 1

\begin{tabular}{|c|c|c|c|c|c|}
\hline Context & $\begin{array}{c}\text { Pavlovian } \\
\text { Conditioning }\end{array}$ & $\begin{array}{l}\text { Instrumental } \\
\text { Acquisition }\end{array}$ & $\begin{array}{l}\text { Instrumental } \\
\text { Extinction }\end{array}$ & \multicolumn{2}{|c|}{ CTX A ${ }^{\text {Tests }}$ CTX B } \\
\hline A & $\begin{array}{l}\text { CS1+ } \\
\text { CS2- }\end{array}$ & $\begin{array}{l}\text { CS1+:R } \\
\text { CS2-:R }\end{array}$ & $\begin{array}{l}\text { CS3-:R } \\
\text { CS4-:R }\end{array}$ & $\begin{array}{l}\text { CS1-:R } \\
\text { CS2-:R }\end{array}$ & $\begin{array}{l}\text { CS3-:R } \\
\text { CS4-:R }\end{array}$ \\
\hline B & $\begin{array}{l}\text { CS3+ } \\
\text { CS4- }\end{array}$ & $\begin{array}{l}\text { CS3+:R } \\
\text { CS4-:R }\end{array}$ & $\begin{array}{l}\text { CS1-:R } \\
\text { CS2-:R }\end{array}$ & $\begin{array}{l}\text { CS1-:R } \\
\text { CS2-:R }\end{array}$ & $\begin{array}{l}\text { CS3-:R } \\
\text { CS4-:R }\end{array}$ \\
\hline
\end{tabular}

Table 1: Design of the experiment. All participants received Pavlovian Training in Contexts A and B. During instrumental acquisition, CS1+ and CS2- were trained in Context A, whereas CS3+ and CS4were trained in Context B. Stimuli CS1 and CS3 were extinguished in the alternative context from that of training ( $B$ and $A$, respectively) and all stimuli were tested in both Contexts (counterbalanced), resulting in a within-subjects $A B B$ vs $A B A$ renewal design. 
Avoidance renewal 23
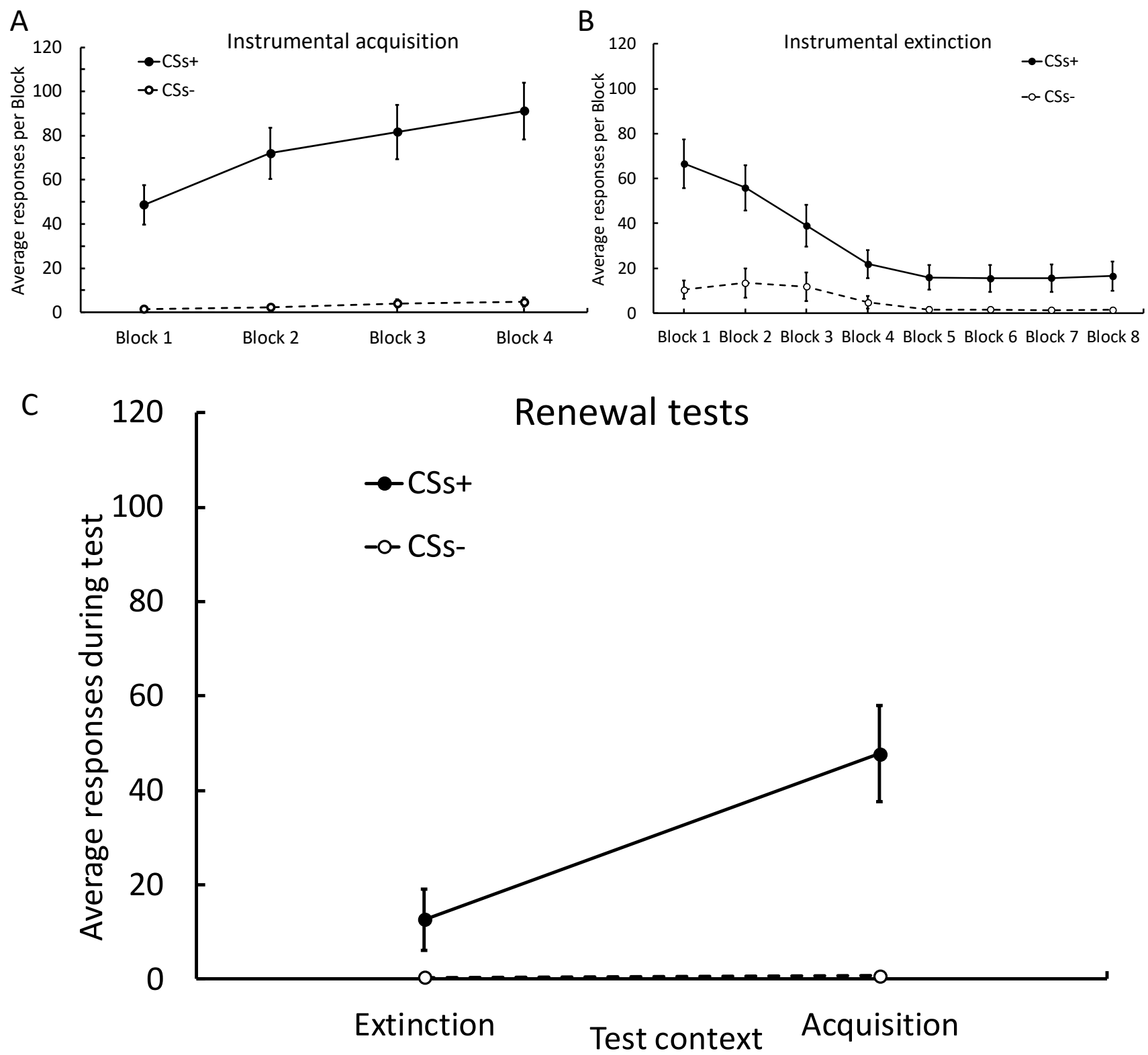

Figure 1. A) Average responses per block during acquisition. There was an increase of avoidance responses upon presentation of CSs+, but not when CSs- were presented. B) Responses during extinction. There was clear extinction of responding during presentations of the CSs+, but a marginal change during presentations of CSs- C) Results of Renewal tests. Responding was higher when participants were tested in the presence of CSs+ in the Acquisition context relative to the Extinction context, but no changes based on context of test were observed for CSs- Error bars represent SE of the mean. 


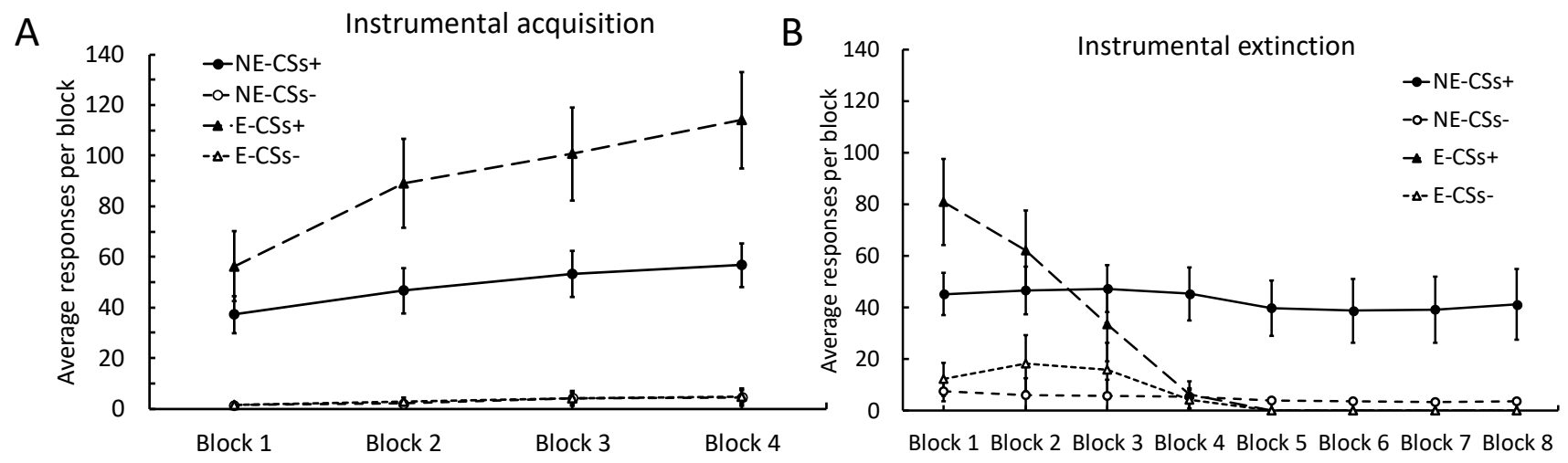

C

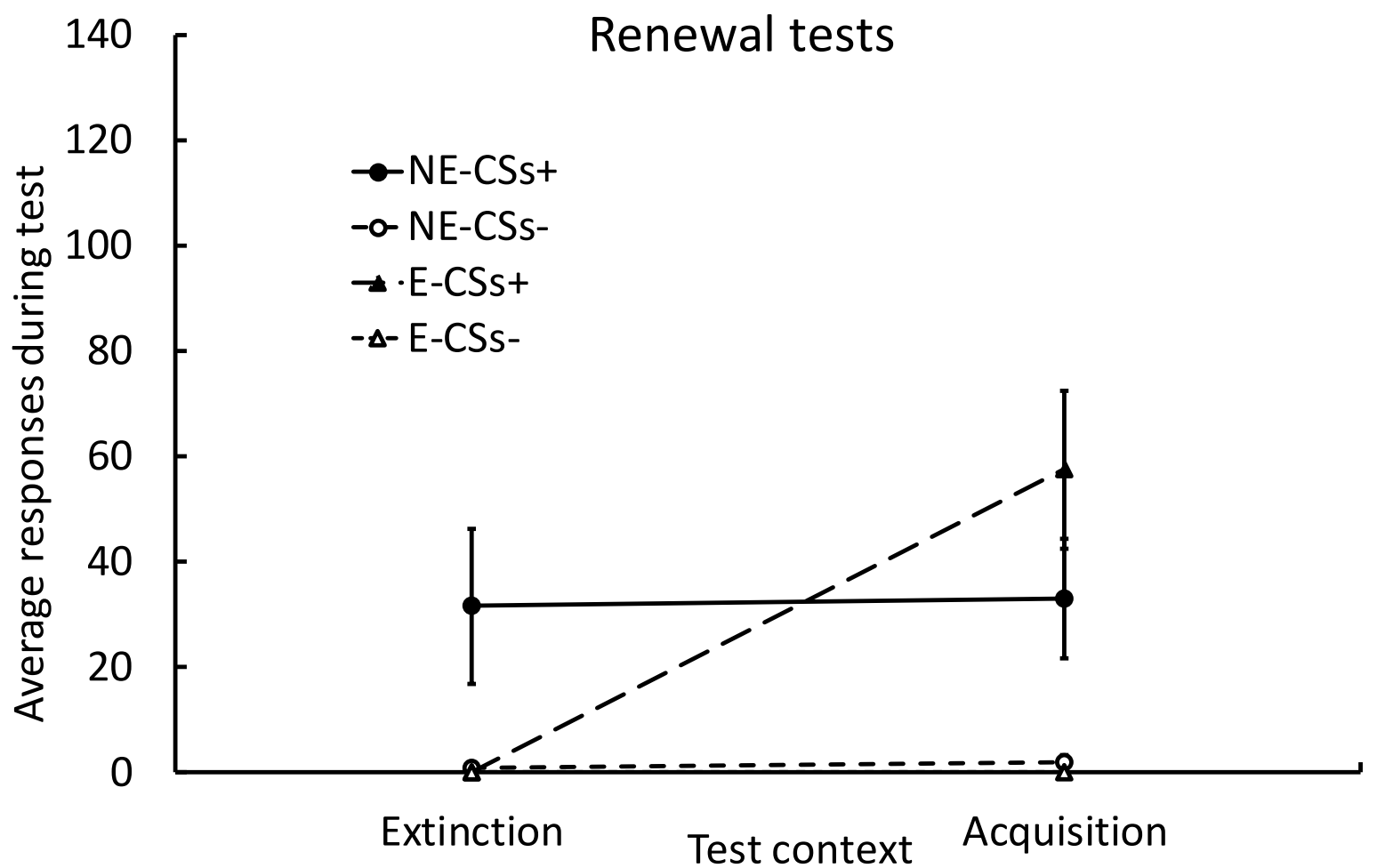

Figure 2. Analysis of individual differences. A) Acquisition of instrumental avoidance based on extinction criteria. $\mathrm{E}=$ Extinction. NE = NoExtinction. B) Performance during extinction based on extinction criteria. C) Performance during Renewal tests based on Extinction criteria. Participants that showed extinction also showed renewal, whilst participants that did not show extinction responded equally in both contexts. Error bars represent SE. 